\title{
Dialysis-related amyloidosis: challenges and solutions
}

\section{R Scarpioni \\ M Ricardi \\ $\checkmark$ Albertazzi \\ $S$ De Amicis \\ F Rastelli \\ L Zerbini}

Department of Nephrology and Dialysis, Azienda Unità Sanitaria Local (AUSL) Hospital "Guglielmo da Saliceto”, Piacenza, Italy
Correspondence: Roberto Scarpioni Department of Nephrology and Dialysis, "Guglielmo da Saliceto" AUSL Hospital, Via Taverna, 49, Piacenza 2912I, Italy

Tel +39523302 I76

Fax +39523 302174

Email rscarpioni@hotmail.com
This article was published in the following Dove Press journal: International Journal of Nephrology and Renovascular Disease 7 December 2016

Number of times this article has been viewed

Abstract: Amyloidosis refers to the extracellular tissue deposition of fibrils composed of lowmolecular-weight subunits of a variety of proteins. These deposits may result in a wide range of clinical manifestations depending upon their type, location, and the amount of deposition. Dialysis-related amyloidosis is a serious complication of long-term dialysis therapy and is characterized by the deposition of amyloid fibrils, principally composed of $\beta 2$ microglobulins $(\beta 2 \mathrm{M})$, in the osteoarticular structures and viscera. Most of the $\beta 2 \mathrm{M}$ is eliminated through glomerular filtration and subsequent reabsorption and catabolism by the proximal tubules. As a consequence, the serum levels of $\beta 2 \mathrm{M}$ are inversely related to the glomerular filtration rate; therefore, in end-stage renal disease patients, $\beta 2 \mathrm{M}$ levels increase up to 60 -fold. Serum levels of $\beta 2 \mathrm{M}$ are also elevated in several pathological conditions such as chronic inflammation, liver disease, and above all, in renal dysfunction. Retention of amyloidogenic protein has been attributed to several factors including type of dialysis membrane, prolonged uremic state and/or decreased diuresis, advanced glycation end products, elevated levels of cytokines and dialysate. Dialysis treatment per se has been considered to be an inflammatory stimulus, inducing cytokine production (such as interleukin-1, tumor necrosis factor- $\alpha$, interleukin-6) and complement activation. The released cytokines are thought to stimulate the synthesis and release of $\beta 2 \mathrm{M}$ by the macrophages and/or augment the expression of human leukocyte antigens (class I), increasing $\beta 2 \mathrm{M}$ expression. Residual renal function is probably the best determinant of $\beta 2 \mathrm{M}$ levels. Therefore, it has to be maintained as long as possible. In this article, we will focus our attention on the etiology of dialysis-related amyloidosis, its prevention, therapy, and future solutions.

Keywords: chronic inflammation, long-term dialysis, $\beta 2$ microglobulin, high-flux dialysis membrane, mineral bone disease

\section{Introduction}

Amyloidosis is a disorder of protein folding in which normally whole proteins or fragments of normally soluble proteins are deposited as abnormal, insoluble fibrils that disrupt the tissue structure, therefore causing disease (Figure 1). In systemic amyloidosis, the deposits may be present in the parenchyma of the viscera and tissues, causing progressive organ dysfunction often leading to death of patients.

The kidneys are one of the most frequent sites of amyloid deposition in amyloidosis AL, AA, and several of the hereditary amyloidoses.

Any organ, except the central nervous system, can be a site of AL amyloid deposition; the kidney is frequently affected in up to $50 \%-80 \%$ of individuals. ${ }^{1}$ 


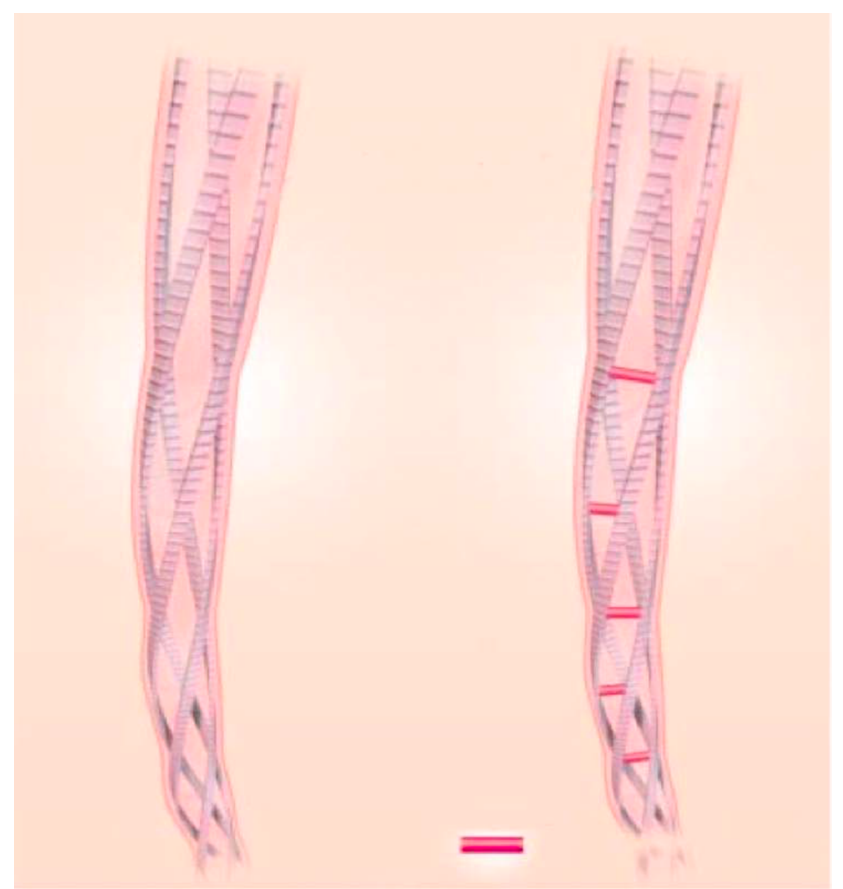

Figure I Structural features of amiloyd: the core structure of all amyloid fibrils consists of antiparallel $\beta$-pleated sheets arranged with their long axes perpendicular to the long axis of the fibril. From $N$ Engl J Med., Merlini G, Bellotti V, Molecular mechanism of amyloidosis., 2003;349(6):583-596. Copyright (C) 2003 Massachusetts Medical Society. Reprinted with permission from Massachusetts Medical Society.'

Dialysis-related amyloidosis (DRA) is a serious complication of both long-term hemodialysis (HD) and peritoneal dialysis (PD).

The incidence of DRA is not known; however, some past studies have suggested an incidence of $>95 \%$ in patients in the US who have been on dialysis for $>15$ years, while European experiences have suggested that DRA can be seen in as much as $20 \%$ of patients after $2-4$ years of HD and in $100 \%$ of patients after 13 years of HD. However, the overall incidence and prevalence of $\beta 2$ microglobulin $(\beta 2 \mathrm{M})$ are not clear. ${ }^{2}$

DRA is characterized by the deposition of amyloid fibril principally composed of $\beta 2 \mathrm{M}$ in the osteoarticular structures and viscera.

$\beta 2 \mathrm{M}$ is a small membrane protein associated with the heavy chains of class I major histocompatibility complex (MHC) on the surface of nucleated cells.

Normally, most of the $\beta 2 \mathrm{M}$ is cleared by glomerular filtration and subsequent proximal tubular reabsorption and catabolism.

In end-stage renal disease (ESRD), as a consequence of marked reduction of catabolism, the plasma levels of $\beta 2 \mathrm{M}$ are elevated and, following a long-time exposure, tissue deposition occurs; in fact, $\beta 2 \mathrm{M}$ is generally rare in the first few years of dialysis.

DRA mainly involves the osteoarticular system (bone, synovium, muscle, tendon, ligaments); the main clinical

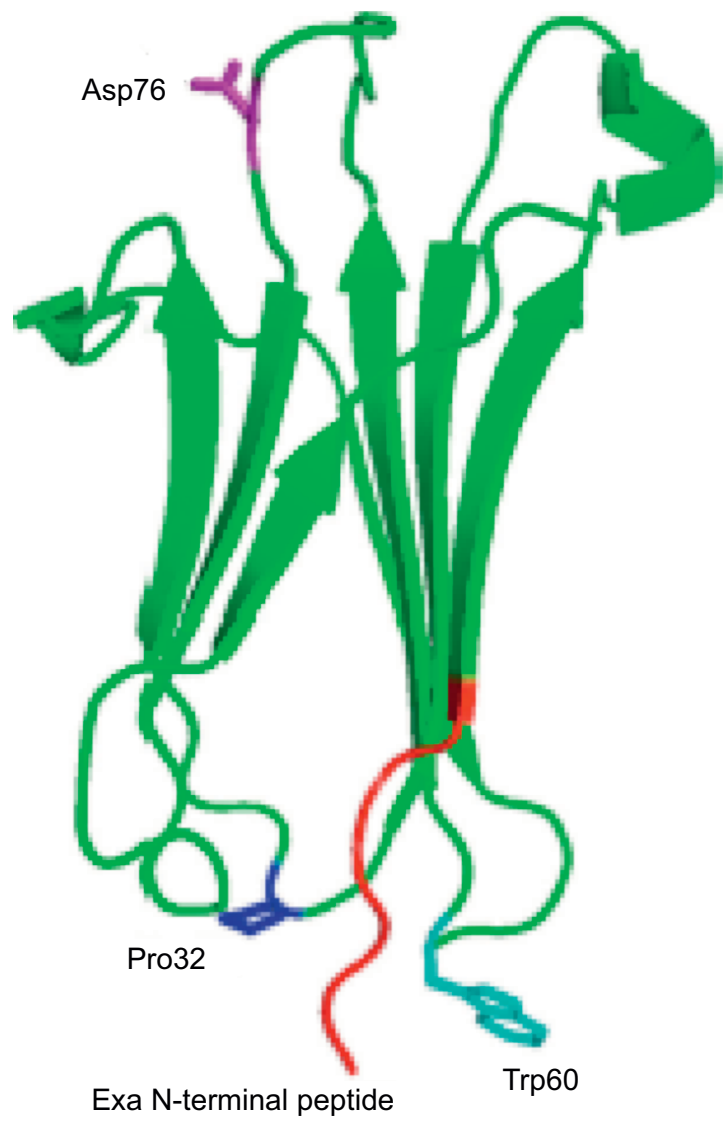

Figure 2 Structure of $\beta 2$ microglobulin. ${ }^{74}$ Abbreviation: PDB, Protein Data Bank.

events are carpal tunnel syndrome (CTS), bone cysts, scapula-humeral periarthritis, joint arthropathy, and destructive spondyloarthropathy.

Unlike the other forms of systemic amyloidosis, visceral involvement, particularly the gastrointestinal one, is less frequent and clinically less relevant. ${ }^{3}$

\section{Pathogenesis}

$\beta 2 \mathrm{M}$ is an $11.8 \mathrm{kDa}$ polypeptide of 99 residues that form the nonvariable chain of MHC class I which is present on the surface of all nucleated cells. ${ }^{4}$

$\beta 2 \mathrm{M}$ has a three-dimensional structure, similar to immunoglobulin superfamily, with seven-stranded $\beta$-sandwich folds stabilized by a single disulfide bond (Figure 2).

Upon dissociation of $\mathrm{MHC}, \beta 2 \mathrm{M}$ is continuously released from the surface of cells into circulation. The production rate of $\beta 2 \mathrm{M}$ is constant, at a level of $2-4 \mathrm{mg} / \mathrm{kg} /$ daily, and in normal subjects, the plasma concentration varies from 1 to $3 \mu \mathrm{g} / \mathrm{mL}$ with a half-life of 3 hours. Most of the $\beta 2 \mathrm{M}$ is eliminated by glomerular filtration and subsequent reabsorption and catabolism by the proximal tubules. As a consequence, the levels of $\beta 2 \mathrm{M}$ are inversely related to the 
glomerular filtration rate; therefore, in ESRD patients, serum $\beta 2 \mathrm{M}$ levels increase up to 60 -fold. ${ }^{5}$

Disruption of tissue architecture by amyloid deposits is considered as the underlying mechanism of organ dysfunction in amyloidoses. However, several authors suggest that amyloidogenic precursor proteins, folding intermediates, and protofilaments have toxicities that are independent of the amyloid deposits and that these toxicities contribute to the disease manifestations as well. Moreover, a lack of correlation between the quantity of amyloid in tissue and organ dysfunction has to be considered. ${ }^{6}$

Cuprophane and cellulose acetate membranes, previously used in conventional HD, have small pores and cannot clear substances with molecular weights higher than $200 \mathrm{Da}$. This makes them impermeable to $\beta 2 \mathrm{M}$, elevating its serum protein levels. Although high-flux $\mathrm{HD}$ and hemodiafiltration have enhanced $\beta 2 \mathrm{M}$ clearance ( $30 \%-40 \%$ higher compared with low-flux HD), the $\beta 2 \mathrm{M}$ production rate is higher than the capacity of removal by all types of dialysis modalities.?

In the long term, sustained high retention of $\beta 2 \mathrm{M}$ causes progressive deposition of $\beta 2 \mathrm{M}$, as amyloid fibrils, in the osteoarticular system, thus resulting in the pathology known as DRA.

However, the precise mechanism of pathogenesis of DRA is not yet fully elucidated and no correlations were found between the serum levels of $\beta 2 \mathrm{M}$ and the onset of DRA.

The propensity of amyloid deposition in bones and ligaments is, in part, explained by the affinity of $\beta 2 \mathrm{M}$ for type I and type II collagen. ${ }^{8}$

As in other types of amyloidosis, other than the retention of protein precursor, several studies have evidenced the importance of biochemical and conformational modifications of $\beta 2 \mathrm{M}$ in the development of DRA. In the serum of uremic patients, but not in healthy subjects, the presence of intermediate misfolded forms of $\beta 2 \mathrm{M}$ was reported by some authors. $^{9}$

Uji et al demonstrated poor removal of intermediate forms compared with native $\beta 2 \mathrm{M}$ among 31 patients on $\mathrm{HD}$ treatment, even when the patients were treated with high-flux HD or hemodiafiltration. ${ }^{10}$

In vitro studies showed that under physiological conditions, enhanced amyloidogenesis is observed in the presence of an increase in equilibrium concentration of a $\beta 2 \mathrm{M}$ intermediate form, named intermediate $\mathrm{T}\left(\mathrm{I}_{\mathrm{T}}\right)$, characterized by a trans isomerization of Pro32. ${ }^{11}$

Moreover, the biochemical characterization of ex vivo amyloid deposits revealed a large quantity $(\sim 30 \%)$ of truncated variant of $\beta 2 \mathrm{M}(\Delta \mathrm{N} 6)$ lacking the six N-terminal residues. Proteolytic cleavage of the six N-terminal residues causes a rearrangement of the structure of $\beta 2 \mathrm{M}$, and also of the intermediate form $\mathrm{I}_{\mathrm{T}}$ and enhances its amyloidogenic properties.

$\Delta \mathrm{N} 6 \beta 2 \mathrm{M}$ shows an affinity for collagen up to tenfold higher than native $\beta 2 \mathrm{M} .{ }^{12} \mathrm{In}$ vitro studies on the collagen surface proved the ability of $\Delta \mathrm{N} 6 \beta 2 \mathrm{M}$ to promote the fibrillar conversion of native $\beta 2 \mathrm{M}$ in physiological environment like the synovial fluid of DRA patients. However, there are no data regarding the timing and the sites where the proteolytic cleavage occurs. ${ }^{13}$

Furthermore, in the amyloid plaques of DRA patients, the presence of $\beta 2 \mathrm{M}$ modified by advanced glycation end products ( $\beta 2 \mathrm{M}-\mathrm{AGE})$ has been demonstrated. ${ }^{14}$

It has been postulated that in uremic patients, elevated serum levels of 3-deoxyglucosone, an intermediate of nonenzymatic Maillard reaction between proteins and carbohydrates, may promote the AGE modification of $\beta 2 \mathrm{M} .{ }^{15}$

The presence of $\beta 2 \mathrm{M}$-AGE leads to an inflammatory response and the recruitment of inflammatory cells, principally monocytes and macrophages, around amyloid deposits. In fact, $\beta 2 \mathrm{M}-\mathrm{AGE}$ is biologically active and interacts with mononuclear phagocytes and synovial fibroblasts through the receptor of advanced glycation end products, stimulating the release of proinflammatory cytokines (chemoattractant factors such as monocyte chemoattractant protein-1) for monocytes/macrophages. ${ }^{16}$

Moreover, dialysis treatment has to be considered as an inflammatory stimulus that induces cytokine production and complement activation; elevated levels of cytokines might play a role in DRA.

The released cytokines, including interleukin (IL)-1, tumor necrosis factor- $\alpha$, and IL-6, are thought to stimulate the synthesis and release of $\beta 2 \mathrm{M}$ by the macrophages and/or augment the expression of MHC class I antigens, increasing $\beta 2 \mathrm{M}$ expression. ${ }^{17}$

This inflammatory component of amyloid deposits contributes to the development of the destructive lesions of bones and joints in DRA patients (Figure 3). Moreover, some authors recently postulated that $\beta 2 \mathrm{M}$ might not only be considered as a uremic toxin marker but also could play an active role in vascular damage in uremic patients, resulting in an increased burden of systemic atherosclerosis. ${ }^{18}$

This is confirmed by a report showing that $\beta 2 \mathrm{M}$ damages the vessels by participating in amyloid formation in the vascular wall. Among 1,704 $\mathrm{HD}$ patients studied in $\mathrm{HEMO}^{19}$ study, the predialysis serum $\beta 2 \mathrm{M}$ predicted mortality and 


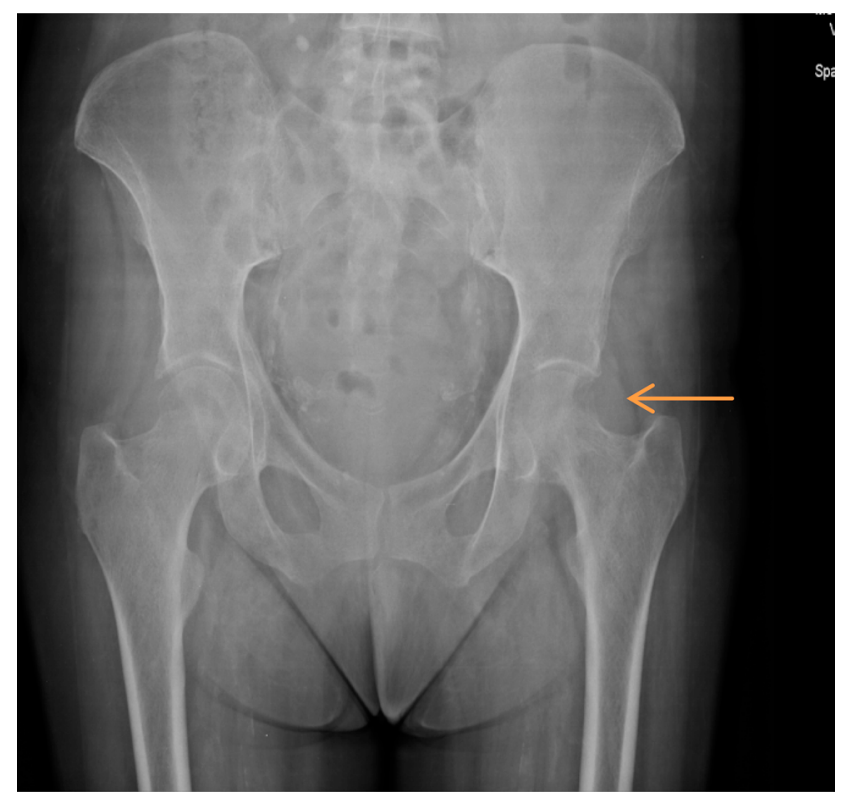

Figure 3 Anteroposterior pelvis radiography of a patient who has been receiving hemodialysis for almost 30 years.

Note: Aggressive osteolytic lesion in the left femoral neck (see arrow) (Courtesy of Department of Nephrology and Dialysis, Hospital “Guglielmo da Saliceto", Piacenza, Italy).

for every $10 \mathrm{mg} / \mathrm{L}$ increase in the $\beta 2 \mathrm{M}$ level, there was a corresponding increase in mortality by $11 \% .^{19}$

\section{Epidemiology and risk factors}

The DRA was recognized as a complication of ESRD as far as 40 years ago. For the first time, in 1975, Warren and Otieno reported a high incidence of CTS in patients on chronic HD. ${ }^{20}$ In 1980, the amyloid deposition was recognized to be associated with CTS and some years later, $\beta 2 \mathrm{M}$ was recognized by some authors as the predominant protein deposited in cases of DRA. ${ }^{5}$

It is not possible to define the effective prevalence of DRA because the "gold standard" diagnostic test, such as biopsy and Congo red staining, is rarely used.

DRA generally occurs in patients who undergo longterm HD for several years, but it has also been observed in patients undergoing continuous ambulatory PD (CAPD) and even in patients with renal failure before the initiation of dialytic therapy. ${ }^{21}$

A large-scale postmortem study showed amyloid deposition in sternoclavicular joint and in the knee in $21 \%, 33 \%, 50 \%, 90 \%$, and $100 \%$ of patients receiving HD for $<2$ years, after 2-4 years, 4-7 years, 7-13 years, and $>13$ years, respectively. ${ }^{2}$

As regards PD, there are little data about the rate of DRA because the dialysis vintage of patients on PD is usually not so prolonged as in HD and there are only a few studies comparing
Table I Risk factors promoting DRA

\begin{tabular}{ll}
\hline Risk factors promoting DRA & Intervention \\
\hline Long-term dialysis treatment & Early kidney transplantation \\
Age of the onset of HD treatment & Not predictable \\
Loss of residual renal function & Avoid excessive intradialytic \\
& ultrafiltration \\
Type of dialysis membrane (low-flux & Use of high-flux biocompatible \\
and bio-incompatible dialysis & membranes and ultrapure \\
membranes) & dialysate \\
\hline
\end{tabular}

Abbreviations: DRA, dialysis-related amyloidosis; HD, hemodialysis.

the prevalence of DRA in HD and PD. Accumulation of amyloid may occur more slowly in patients treated by CAPD because serum $32 \mathrm{M}$ levels are lower in patients treated by CAPD in comparison to patients on HD with low-flux membranes. ${ }^{22}$

In 2008, a study of small sample size reported that the development of DRA did not differ significantly between patients treated by HD and CAPD for a moderate length of time ( $<5$ years) with regard to the thickness of supraspinatus tendon. ${ }^{23}$

On the contrary, in a recent retrospective study, Hayami et al found that the most serious complication of DRA, that is, destructive spondyloarthropathy, was significantly more common in patients on long-term PD than in hemodialyzed patients. The authors hypothesized this fact to be induced by the dialysis method and, in particular, by the continuous intra-abdominal stress due to the infusion of large volume of fluids, as in PD. ${ }^{24}$

Risk factors promoting DRA are given in Table 1; they are as follows:

- Long-term dialysis treatment: In Jadoul et al's study, increasing prevalence of histologically proven DRA with dialysis vintage was demonstrated. ${ }^{2}$ The ameliorations in dialysis techniques grow survival rates of hemodialyzed patients and, as a consequence, the risk of DRA. ${ }^{25}$

- Age of onset of HD treatment: It is considered as an independent risk factor. Young people are less liable to this complication than older people. Since HD treatment is now more frequently started in older patients and survival in hemodialyzed patients is more long-lasting (because of better renal disease treatment), DRA may onset more frequently in older patients. ${ }^{26}$

- Absence of residual renal function (RRF): $\beta 2 \mathrm{M}$ is cleared by glomerular filtration and subsequent proximal tubular reabsorption and catabolism; therefore, decrease in kidney function, and the consequent reduction in RRF, leads to progressive increase in the plasma levels of $\beta 2 \mathrm{M} .{ }^{27}$ 
As a consequence of this, the more is the RRF and urine output, the better is the clearance of $\beta 2 \mathrm{M}$ and the defense against the development of DRA.

- Use of low-flux dialysis membrane: Levels of $\beta 2 \mathrm{M}$ are significantly lower (by 30\%) in patients treated with highflux dialysis membrane compared with that in patients treated with low-flux membranes. In fact, the molecular weight of $\beta 2 \mathrm{M}$ is higher than the cut-off level of porosity of low-flux membranes; on the contrary, high-flux membranes remove $\beta 2 \mathrm{M}$ by absorption and convection. Moreover, it is demonstrated that high-flux biocompatible membranes are more efficient in preserving the RRF than low-flux cellulosic membranes, and therefore significantly reduce the incidence of DRA. ${ }^{28}$

- Use of bio-incompatible dialysis membrane: The membrane effect is a potential influence on DRA. Bioincompatible membranes, such as cuprophane and cellulose acetate membranes, have small pores and cannot clear substances of molecular weights higher than $200 \mathrm{Da}$. Furthermore, it leads to a marked rise in $\beta 2 \mathrm{M}$ plasma levels. It has been demonstrated by in vitro experiments that mononuclear cells in contact with cellulosic membranes promote the production of IL- 6 and the transcription and release of $\beta 2 \mathrm{M}$ from the monocytes. ${ }^{29}$ This phenomenon is more marked in the presence of products of complement activation. Therefore, repeated exposure of the blood of patient to bio-incompatible membranes may promote the inflammatory response, aggravate the oxidative stress of uremia, and play a role in the development of amyloid disease.

\section{Clinical manifestations of DRA}

Patients affected by DRA suffer from symptoms related to infiltration of $\beta 2 \mathrm{M}$ in soft tissues and visceral organs. The frequently involved articulations are arm joints, such as scapulohumeral and the carpal bones, and the cervical neck. ${ }^{30}$ Gastrointestinal involvement is rare and generally occurs with pseudo-obstruction syndrome due to gastric or colonic dilatation. ${ }^{31}$

More serious complications have been described, such as gastrointestinal bleeding or ischemic bowel complicated with perforation. ${ }^{32}$

Symptoms of visceral involvement are uncommon and highly nonspecific, such as difficult swallowing or pain with swallowing. Macroglossia is a suspicious sign for gastrointestinal involvement. ${ }^{33}$

$\beta 2 \mathrm{M}$ amyloid could be potentially deposited everywhere (ie, in the rectal mucosa, liver, spleen, and blood vessels), but cardiac involvement is the most fearsome because of congestive heart failure and fatal arrhythmias. It is to be considered that cardiac involvement is frequent in $\mathrm{AL}$ amyloidosis, but is rare in $\beta 2 \mathrm{M}$ amyloidosis as well as in AA amyloidosis. ${ }^{34}$

Serum $\beta 2 \mathrm{M}$ levels are increased in patients with ESRD on dialysis treatment; levels in plasma typically range from 30 to $50 \mathrm{mg} / \mathrm{L}$, much higher than the normal values (between 0.8 and $3.0 \mathrm{mg} / \mathrm{L}) .{ }^{4}$ However, high plasma $\beta 2 \mathrm{M}$ level is not a reliable predictive marker of DRA and several patients with high plasma $\beta 2 \mathrm{M}$ concentration have no DRA. ${ }^{35}$ According to Kidney Disease Outcomes Quality Initiative guidelines, tissue biopsy is the "gold standard" test to detect $\beta 2 \mathrm{M}$ for diagnosing DRA. Similar to other amyloid fibril proteins, in Congo red staining, $\beta 2 \mathrm{M}$ is Congo red positive and exhibits apple-green birefringence under polarized light. ${ }^{36}$ The type of amyloid fibril proteins cannot be recognized by standard immunofluorescence which is negative and nonspecific, but can be recognized by specific immunohistochemistry for $\beta 2 \mathrm{M}$ and/or laser microdissection-mass spectrometry. In electron microscopy, the amyloid fibrils are extracellular, straight, randomly arranged, measuring 9-11 nm in diameter. ${ }^{37}$ Abdominal fat pad aspiration is not useful in diagnosing DRA, but it is used in diagnosing AL amyloidoses sometimes. Physicians should suspect DRA when joint symptoms occur in HD patients; scapulohumeral periarthritis could be induced by amyloid infiltration of rotator cuff muscles. ${ }^{38}$ In patients on dialysis for decades, even scapulohumeral destruction may occur (Figure 4).

Bilateral shoulder pain is elicited by abduction of arm, whose motion is very limited. Lying on supine position worsens the pain, for instance, during rest at night, sometimes making the dialysis session poorly tolerated. ${ }^{39}$ Physical examination could reveal the "shoulder pad sign": the shoulders struck by DRA appear hypertrophied due to thickening and/or deposition of amyloid between the muscles and tendons of the rotator cuff. The thickness of the rotator cuff could be confirmed by ultrasonography, which may detect pads deposited between the muscles and tendons. ${ }^{40}$ Even magnetic resonance imaging could easily show thickening of the supraspinatus and/or subscapularis tendon. ${ }^{41}$ Arm tendons could be involved in $\beta 2 \mathrm{M}$ deposition; bicipital tendon becomes tender to palpation, which could be shown even by ultrasonography or magnetic resonance imaging.

CTS is a typical target of DRA; patients often suffer from hand pain, numbness, and dysesthesias in the distribution of the median nerve, which means decreased sensation in the thumb and index, middle, and ring fingers. ${ }^{6}$ In order to have a complete evaluation for CTS, nerve conduction studies are necessary to establish the severity of median nerve 


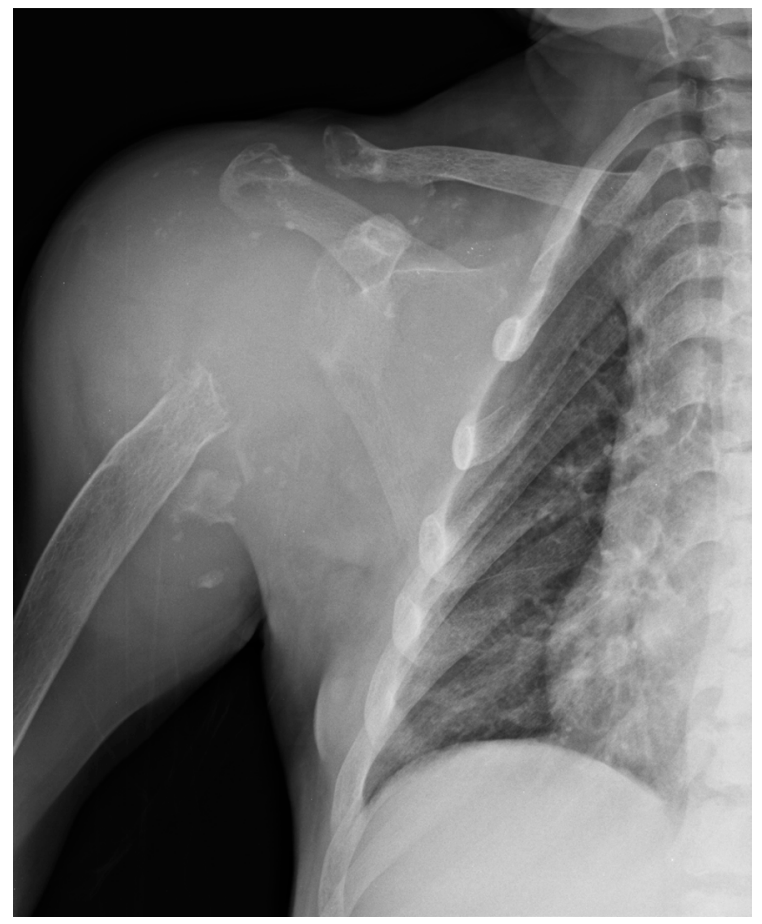

Figure 4 Anteroposterior right shoulder radiography of a male patient on longterm renal replacement treatment.

Notes: DRA totally destroyed right humerus head. Deltoid and proximal humerus area is occupied by amorphous irregular lesion (Courtesy of Department of Nephrology and Dialysis, Hospital “Guglielmo da Saliceto”, Piacenza, Italy). Abbreviation: DRA, dialysis-related amyloidosis.

injury. ${ }^{42}$ Electrodiagnosis of CTS helps in observing an impaired median nerve conduction across the carpal tunnel in the context of normal conduction elsewhere. Delayed distal latencies and slowed conduction velocities represent a mild damage, corresponding to compression of myelin sheath. A reduction of compound motor or sensory action potential amplitude means severe damage and corresponds to axon loss. ${ }^{43}$ Median sensory response is recorded from digit two or three while stimulating the wrist, whereas during motor conduction study, the stimulus is at the wrist and elbow and the recording is from the abductor pollicis brevis. Results obtained are compared with age-dependent normal values, and with ulnar and radial sensory responses and ulnar motor conduction study. This is an important way to recognize CTS with a limited damage to median nerve or to diagnose peripheral neuropathy involving other hand nerves. When conditions other than CTS are suspected (namely, polyneuropathy, plexopathy, and radiculopathy), electromyography could reveal pathological changes (either active denervation or denervation with subsequent reinnervation) in the muscles innervated by the median nerve, typically the abductor pollicis brevis muscle. ${ }^{44}$ When CTS is overt, atrophy of thenar eminence muscles appears.
DRA-CTS is more frequent on the side of vascular access, and symptoms could worsen during dialysis, in part, due to steal syndrome. ${ }^{45}$

In HD patients suffering from CTS, surgery is better than conservative measures since DRA is progressive and will worsen over time. Surgery performed within 3 years of CTS diagnosis may increase the chances of success, whereas having repeated numbness, muscle weakness, or atrophy and very poor median nerve conduction are negative predictive factors of the outcome of surgery. Surgery in HD patients with CTS could be initially successful, but the condition deteriorates in about half of these patients after around 18 months. In traditional open surgical procedure, transverse carpal ligament is cut in order to release the median nerve. ${ }^{46}$ Recent surgical trend involves mini-open and endoscopic approaches to reduce recovery time and pain. However, presently, there is no evidence of any significant long-term advantages of less-invasive procedures than open release surgery. ${ }^{47}$

When amyloid deposition occurs along flexor tendons, physicians could detect the pathognomonic "guitar string" sign; when the fingers are extended, the flexor tendons become prominent due to amyloid deposition in soft tissue of the palm ${ }^{48}$ (Figure 5).

When the clinical picture worsens, DRA patients' fingers could have irreducible flexion contractures. ${ }^{49}$ Cervical neck pain may reveal destructive spondyloarthropathy induced by $\beta 2 \mathrm{M}$ exposure, with intervertebral disk space loss and erosion of the consecutive vertebral endplates. ${ }^{50}$

Computed tomography scan is essential for the differential diagnosis and to rule out the possibility of infectious diskitis. ${ }^{51} \mathrm{~A}$ very rare DRA complication induced by $\beta 2 \mathrm{M}$ amyloid deposition in the spinal cord of patients undergoing HD longer than 20 years is quadriparesis or quadriplegia. ${ }^{52}$

The bone cysts formed in $\beta 2 \mathrm{M}$ amyloidosis involve the bones above all the axial skeeton: humeral head, carpal bones, hand phalanges, femoral neck, acetabulum, tibial plateau, and distal radius (Figure 6). ${ }^{53}$

DRA-bone cysts appear as radiolucent lesions with thin sclerotic margins on conventional radiography. They may be clinically distinguished from the brown tumors of hyperparathyroidism by their rapid rate of enlargement and the increase in number over time. Patients with femoral neck cysts run the risk of pathological fractures. ${ }^{54}$

Strategies of clinical surveillance are very difficult because DRA often causes nonspecific symptoms. Moreover, the pathognomonic signs pointed above (shoulder pad sign or guitar string) are uncommon and take several years to develop. So, diagnosis is often delayed until many investigations are 


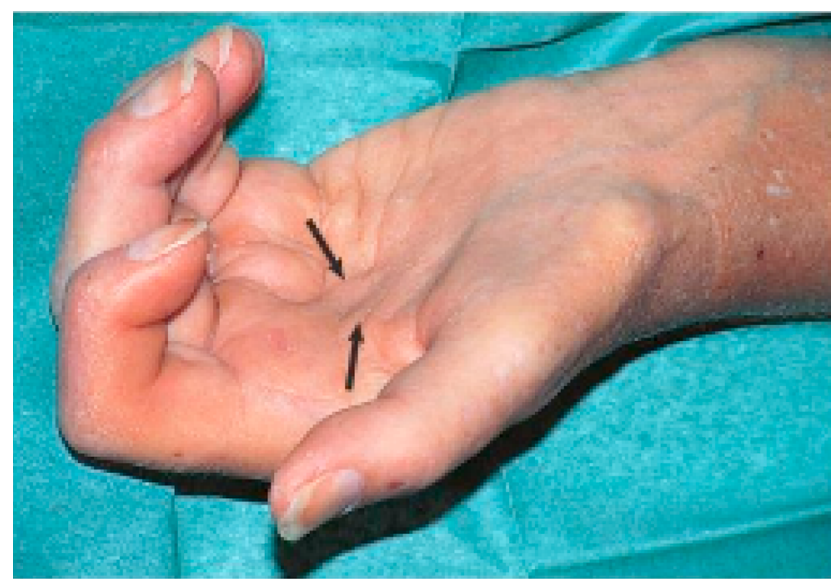

Figure 5 Hand involvement in DRA

Notes: Hand of a long-term HD patient in maximal extension. You can observe the typical "guitar string sign", the prominence of shrunken flexor tendons (see arrows). Reprinted from Comprehensive Clinical Nephrology. 5th ed. Martin KJ, Floege J, Ketteler M. Bone and mineral metabolism in chronic kidney disease, Chapter 85, 984-999, Copyright (2014), with permission from Elsevier..$^{48}$

Abbreviations: DRA, dialysis-related amyloidosis; HD, hemodialysis.

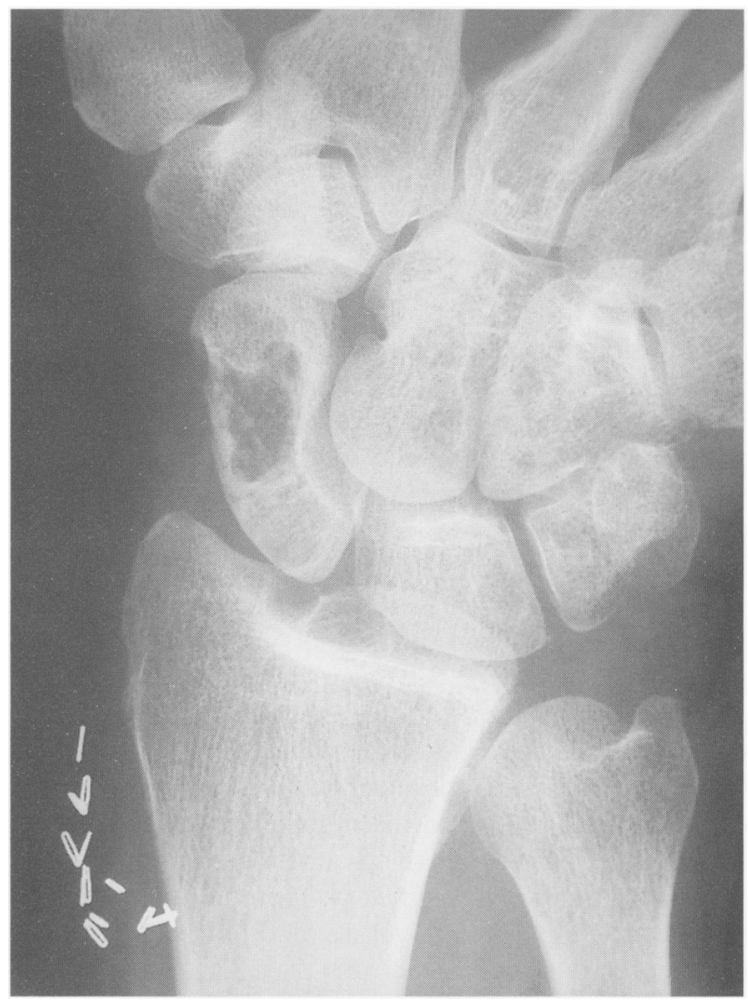

Figure 6 Anteroposterior radiography of a hand with classic amyloid cysts throughout the carpus and distal radius, typical locations of DRA bone cysts.

Note: The scaphoid presents a large cyst. Copyright (c) 1996. lowa University. Reproduced from Fitzpatrick DC, Jebson PJ, Madey SM, Steyers CM. Upper extremity musculoskeletal manifestations of dialysis-associated amyloidosis. lowa Orthop J. 1996; 16:135-138.53

Abbreviation: DRA, dialysis-related amyloidosis.

performed, often culminating in a tissue biopsy. A suggestion could be to recognize the joint symptoms in HD patients through a frequent clinical examination and to suspect DRA related to patient dialysis vintage.
If the suspicion of DRA is valid, physicians have to reexamine any available tissue biopsies.

In order to achieve an early diagnosis of DRA, it could be useful to have an early diagnosis of dialysis-related CTS through ultrasonography with improved resolution using a high-frequency probe. Recently, Yamazaki et al observed that the median nerve compression rate, measured by an improved ultrasound device, significantly correlated with clinical symptoms, medical history, and serological features $(\beta 2 \mathrm{M}$ level $\geq 20 \mathrm{mg} / \mathrm{L}$ ) associated with dialysis-related CTS. The compression rate of the nerve was calculated by measuring the smallest diameter of the compressed nerve and the largest diameter of the unaffected part. ${ }^{55}$ Patients with DRA need long-term surveillance and, in the shorter term, 6-monthly specialist follow-up, so as to evaluate the progression rate of the disease.

\section{Prevention and treatment}

Since there is no etiological medical or pharmacological cure for DRA, removal of plasmatic $\beta 2 \mathrm{M}$ through dialysis sessions remains the cornerstone of prevention and treatment of DRA. In fact, in the last few years, wider use of highly biocompatible and high-flux membranes for dialysis treatment has decreased the incidence of DRA worldwide. ${ }^{56}$

Successful renal transplantation causes reduction in $\beta 2 \mathrm{M}$ levels; it has been shown that after some years, in a patient with a well-functioning renal graft, the amyloid deposits may also regress. ${ }^{57}$

On the other hand, some authors reported that in patients who underwent renal transplantation, progression of the disease can be halted, but regression is unlikely. ${ }^{58}$ The benefits of $\mathrm{PD}$ in reducing $\beta 2 \mathrm{M}$ deposition, in view of its lower levels in PD patients, are not widely accepted. ${ }^{59}$

Considering that kidney transplantation is generally believed to be the optimal form of renal replacement therapy, it is fair to assume that in patients affected by DRA, the best treatment option is renal transplantation. Unfortunately, the majority of ESRD patients are not appropriate candidates for transplantation because of comorbid conditions, advanced age, and dialysis vintage. Moreover, the shortage of kidney donors, especially in some countries, makes it hard to consider renal transplantation a feasible treatment option for DRA. ${ }^{60}$

In order to prevent and slow the progression of DRA in patients on HD, the dialysis treatment should be optimized in order to achieve the maximum decrease in plasmatic $\beta 2 \mathrm{M}$ levels through the maximum clearance of this protein. The dialysis modality, the duration, and the frequency drive $\beta 2 \mathrm{M}$ clearance. 
As suggested by the 2003 Kidney Disease Outcomes Quality Initiative guidelines, for HD patients with DRA, highly biocompatible and high-flux membranes should be used in dialysis. ${ }^{34}$

In fact, several studies have demonstrated that the serum levels of $\beta 2 \mathrm{M}$ are lower in patients treated with high-flux biocompatible membranes. ${ }^{61,62}$ Moreover, as shown by Furuya et al, the use of high-purity dialysate with lower endotoxin level than the conventional dialysate is beneficial during HD treatment because of reduction of serum $\beta 2 \mathrm{M}$, pentosidine, C-reactive protein, and IL-6 which probably accelerate amyloid deposition. ${ }^{63}$

Since both hemofiltration and hemodiafiltration are able to remove $\beta 2 \mathrm{M}$ significantly, some studies have reported a lower incidence of CTS in patients treated with these two dialysis methods; however, a clear benefit of these two dialytic techniques versus biocompatible high-flux HD performed at high blood flow rate has not been demonstrated. ${ }^{64,65}$

In order to achieve a better clearance of $\beta 2 \mathrm{M}$, it is certainly useful to increase the duration and frequency of dialysis; thus, the onset and development of DRA is delayed. This observation could justify why either nocturnal or short daily HD is better than conventional thrice-weekly dialysis to ameliorate DRA. ${ }^{6}$

Some studies suggested that the incidence of DRA is similar in HD and peritoneal patients. During PD, only a small amount of $\beta 2 \mathrm{M}$ is cleared daily because of slow convective transport and dialysate flow rate, despite the peritoneal membrane being highly permeable to small proteins and having the highest biocompatibility. Some authors believe that the progression of DRA is greater in HD patients, most likely because peritoneal patients show better maintenance of RRF. ${ }^{67}$

In fact, RRF is reported to be probably the best determinant of $\beta 2 \mathrm{M}$ removal. ${ }^{68}$

In any case, it is important to consider that this comparison between the two dialysis methods might be influenced by the generally shorter average duration of PD treatment.

The use of $\beta 2 \mathrm{M}$ adsorption column during HD treatment is a way to directly remove serum $\beta 2 \mathrm{M}$, and thus, it is able to improve the clearance of the protein. Adsorption of this specific protein by the column is a result both of hydrophobic and molecular size-dependent interactions between the ligand, placed in the column, and $\beta 2 \mathrm{M}$. Several Japanese authors have reported that the use of this procedure in patients with DRA seems to be associated with a better control in symptoms versus traditional dialysis alone. ${ }^{69-71}$
Palliative treatment of DRA is based on reduction of symptoms related to the disease. The most debilitating clinical manifestations of DRA are CTS and disposition to pathological fractures due to bone cysts. Analgesics, nonsteroidal anti-inflammatory drugs, and steroids may be useful for controlling articular and bone pain.

Surgical correction of CTS with debridement of hypertrophied synovium infiltrated by amyloid is effective in reducing median nerve compression. Unfortunately, CTS often recurs within a few years after surgery. Scapulohumeral periarthritis often requires arthroscopic or open surgery by which the synovium infiltrated by $\beta 2 \mathrm{M}$ is cleared. Bone grafting of skeletal segments with amyloid cysts or replacement of affected joints is useful in relieving pain and restoring mobility. 72,73

\section{Conclusion}

The immune system is chronically stimulated in chronic kidney disease, and dialysis treatment represents a further additive factor in promoting inflammation. The role of endotoxin and bacterial contamination of the dialysate may represent a piece of this complicated puzzle, contributing to complement activation, oxidative stress, cytokine stimulation, as well as $\beta 2 \mathrm{M}$ amyloidosis deposition.

Dialysis treatment (PD or HD with ultrapure dialysate or with more biocompatible and high-flux membranes) may represent a helpful strategy in reducing amyloid deposition; but all strategies to maintain the residual renal function as long as possible must be put in place. Early renal transplantation program should be pursued as soon as possible due to its ability to cause increased reduction of $\beta 2 \mathrm{M}$ levels.

No medical treatment presently exists to reverse or alter the course of $\beta 2$ amyloidosis. Medical therapy is limited to symptomatic approaches that ameliorate joint pain and inflammation. Surgical intervention may only be confined to carpal tunnel decompression of the median nerve or release of the transverse carpal ligaments, flexor tenosynovectomy or percutaneous first annular pulley release or total joint replacement, and may be effective in alleviating pain and restoring the function.

Unfortunately, orthopedic interventions have high failure rates in DRA, compared with the rates in the general population.

However, it has to be remembered that progression of the disease can be halted, but its regression is unlikely with all the therapeutic strategies. So, the main purpose of avoiding $\beta 2 \mathrm{M}$ amyloid deposit is the prevention of its deposition, intervening early on modifiable factors, as reported in Table 1. 


\section{Disclosure}

The authors report no conflicts of interest in this work.

\section{References}

1. Merlini G, Bellotti V. Molecular mechanism of amyloidosis. $N$ Engl $J$ Med. 2003;349(6):583-596.

2. Jadoul M, Garbar C, Noël H, et al. Histological prevalence of beta 2-microglobulin amyloidosis in hemodialysis: a prospective postmortem study. Kidney Int. 1997;51(6):1928-1932.

3. Athanasou NA, Ayers D, Rainey AJ, Oliver DO, Duthie RB. Joint and systemic distribution of dialysis amyloid. $Q \mathrm{~J} \mathrm{Med}$. 1991;78(287): 205-214.

4. Vincent C, Revillard JP. Beta-2-microglobulin and HLA-related glycoproteins in human urine and serum. Contrib Nephrol. 1981;26:66-88.

5. Gejyo F, Yamada T, Odani S, et al. A new form of amyloid protein associated with chronic haemodialysis was identified as beta 2 microglobulin Biochem Biophys Res Commun. 1985;129(3):701-706.

6. Lobato L, Beirao I, Guimaraes SM, Droz D, Guimarães S, Grünfeld JP, Noël LH. Familial amyloid polyneuropathy type I (Portuguese): distribution and characterization of renal amyloid deposits. Am J Kidney Dis. 1998;31(6):940-946.

7. Dember LM, Jaber BL. Dialysis-related amyloidosis: late finding or hidden epidemic? Semin Dial. 2006;19(2):105-109.

8. Giorgetti S, Rossi A, Mangione P, et al. Beta2-microglobulin isoforms display an heterogeneous affinity for type I collagen. Protein Sci. 2005; 14(3):696-702.

9. Heegaard NH, Sen JW, Kaarsholm NC, Nissen MH. Conformational intermediate of the amyloidogenic protein beta 2-microglobulin at neutral pH. J Biol Chem. 2001;276(35):32657-32662.

10. UjiY, Motomiya Y, Ando Y. A circulating beta 2-microglobulin intermediate in hemodialysis patients. Nephron Clin Pract. 2009;111(3):c173-c181.

11. Jahn TR, Parker MJ, Homans SW, Radford SE. Amyloid formation under physiological conditions proceeds via a native-like folding intermediate. Nat Struct Mol Biol. 2006;13(3):195-201.

12. Eichner T, Radford SE. A generic mechanism of beta2-microglobulin amyloid assembly at neutral $\mathrm{pH}$ involving a specific proline switch. J Mol Biol. 2009;386(5):1312-1326.

13. Eichner T, Kalverda AP, Thompson GS, Homans SW, Radford SE. Conformational conversion during amyloid formation at atomic resolution. Mol Cell. 2011;41(2):161-172.

14. Miyata $T$, Oda $\mathrm{O}$, Inagi $\mathrm{R}$, et al. Beta 2-Microglobulin modified with advanced glycation end products is a major component of hemodialysisassociated amyloidosis. J Clin Invest. 1993;92(3):1243-1252.

15. Tsukushi S, Katsuzaki T, Aoyama I, Takayama F, Miyazaki T, Shimokata K, Niwa T. Increased erythrocyte 3-DG and AGEs in diabetic hemodialysis patients: role of the polyol pathway. Kidney Int. 1999;55(5): 1970-1976.

16. Hou FF, Jiang JP, Guo JQ, et al. Receptor for advanced glycation end products on human synovial fibroblasts: role in the pathogenesis of dialysis-related amyloidosis. J Am Soc Nephrol. 2002;13(5):1296-1306.

17. Schaeffer J, Floege J, Ehlerding G, Koch KM. Pathogenetic and diagnostic aspects of dialysis-related amyloidosis. Nephrol Dial Transplant. 1995;10 (Suppl 3):S4-S8.

18. Zumrutdal A. Role of $\beta 2$-microglobulin in uremic patients may be greater than originally suspected. World J Nephrol. 2015;4(1):98-104.

19. Cheung AK, Rocco MV, Yan G, et al. Serum beta-2 microglobulin levels predict mortality in dialysis patients: results of the HEMO study. $J \mathrm{Am}$ Soc Nephrol. 2006;17:546-555.

20. Warren DJ, Otieno LS. Carpal tunnel syndrome in patients on intermittent haemodialysis. Postgrad Med J. 1975;51(597):450-452.

21. Zingraff JJ, Noel LH, Bardin T, Atienza C, Zins B, Drueke TB, Kuntz D. Beta 2-microglobulin amyloidosis in chronic renal failure. $N$ Engl $J$ Med. 1990;323(15):1070-1071.

22. Miyata T, Jadoul M, Kurokawa K, Van Ypersele de Strihou C. Beta-2 microglobulin in renal disease. J Am Soc Nephrol. 1998;9(9):1723-1735.
23. Dervisoglu E, Anik Y, Erdogan S, Akansel G, Yilmaz A. Beta2microglobulin amyloidosis in hemodialysis and peritoneal dialysis patients. Ther Apher Dial. 2008;12(4):306-310.

24. Hayami N, Hoshino J, Suwabe T, et al. Destructive spondyloarthropathy in patients on long-term peritoneal dialysis or hemodialysis. Ther Apher Dial. 2015;19(4):393-398.

25. Schiffl H. Impact of advanced dialysis technology on the prevalence of dialysis-related amyloidosis in long-term maintenance dialysis patients. Hemodial Int. 2014;18(1):136-141.

26. Van Ypersele de Strihou C, Jadoul M, Malghem J, Maldague B, Jamart J. Effect of dialysis membrane and patient's age on signs of dialysis-related amyloidosis. The Working Party on Dialysis Amyloidosis. Kidney Int. 1991;39(5):1012-1019.

27. McCarthy JT, Williams AW, Johnson WJ. Serum beta 2-microglobulin concentration in dialysis patients: importance of intrinsic renal function. J Lab Clin Med. 1994;123(4):495-505.

28. Hartmann J, Fricke H, Schiffl H. Biocompatible membranes preserve residual renal function in patients undergoing regular hemodialysis. $\mathrm{Am}$ J Kidney Dis. 1997;30(3):366-373.

29. Memoli B, Libetta C, Rampino T, et al. Interleukin-6 production of uraemic haemodialysed patients: effects of different membranes. Nephrol Dial Transplant. 1991;6 (Suppl 2):96-98.

30. Fenves AZ, Emmett M, White MG, Greenway G. Carpal tunnel syndrome with cystic bone lesions secondary to amyloidosis in chronic hemodialysis patients. Am J Kidney Dis. 1986;7(2):130-134.

31. Ikegaya N, Kobayashi S, Hishida A, Kaneko E, Furuhashi M, Maruyama Y. Colonic dilatation due to dialysis-related amyloidosis. Am J Kidney Dis. 1995;25(5):807-809.

32. Dulgheru EC, Balos LL, Baer AN. Gastrointestinal complications of beta2-microglobulin amyloidosis: a case report and review of the literature. Arthritis Rheum. 2005;15;53(1):142-145.

33. Sethi D, Hutchison AJ, Cary NR, Brown EA, Curtis JR, Woodrow DF, Gower PE. Macroglossia and amyloidoma of the buttock: evidence of systemic involvement in dialysis amyloid. Nephron. 1990;55(3): 312-315.

34. Scarpioni R, Ricardi M, Albertazzi V. Secondary amyloidosis in autoinflammatory diseases and the role of inflammation in renal damage. World J Nephrol. 2016;5(1):66-75.

35. Kazama JJ, Yamamoto S, Takahashi N, Ito Y, Maruyama H, Narita I, Gejyo F. Abeta-2M-amyloidosis and related bone diseases. J Bone Miner Metab. 2006;24(2):182-184.

36. National Kidney Foundation. K/DOQI clinical practice guidelines for bone metabolism and disease in chronic kidney disease. Am J Kidney Dis. 2003;42 (4 Suppl 3):S1-S201.

37. Fogo AB, Lusco MA, Najafian B, Alpers CE. AJKD atlas of renal pathology: hereditary and other non-AL amyloidoses. Am J Kidney Dis. 2015;66(6):e49-51.

38. Chattopadhyay C, Ackrill P, Clague RB. The shoulder pain syndrome and soft-tissue abnormalities in patients on long-term haemodialysis Br J Rheumatol. 1987;26(3):181-187.

39. Kay J. B2-microblogulin amyloidosis. Amyloid Int J Exp Clin Invest. 1997;4:187-211.

40. Sommer R, Valen GJ, Ori Y, Weinstein T, Katz M, Hendel D, Korzets A. Sonographic features of dialysis-related amyloidosis of the shoulder. J Ultrasound Med. 2000;19:765-770.

41. Slavotinek JP, Coates PT, McDonald SP, Disney AP, Sage MR. Shoulder appearances at MR imaging in long-term dialysis recipients. Radiology. 2000;217(2):539-543.

42. Jablecki CK, Andary MT, Floeter MK, et al. Practice parameter: electrodiagnostic studies in carpal tunnel syndrome. Report of the American Association of Electrodiagnostic Medicine, American Academy of Neurology, and the American Academy of Physical Medicine and Rehabilitation. Neurology. 2002;58(11):1589-1592.

43. Jablecki CK, Andary MT, So YT, Wilkins DE, Williams FH. Literature review of the usefulness of nerve conduction studies and electromyography for the evaluation of patients with carpal tunnel syndrome. Muscle Nerve. 1993;16(12):1392-1414. 
44. Preston DC, Shapiro BE. Median neuropathy at the wrist. In: Electromyography and Neuromuscular Disorders: ClinicalElectrophysiologic Correlations. 3rd ed. Elsevier, New York, NY, USA; 2013:267.

45. Laurent G, Calemard E, Charra B. Dialysis related amyloidosis. Kidney Int Suppl. 1988;24:S32-S34.

46. Keith MW, Masear V, Chung KC, et al; American Academy of Orthopaedic Surgeons. American Academy of Orthopaedic Surgeons clinical practice guidelines on the treatment of carpal tunnel syndrome. J Bone Joint Surg Am. 2009;91(1):218-219.

47. Huisstede BM, Randsdorp MS, Coert JH, Glerum S, van Middelkoop M, Koes BW. Carpal tunnel syndrome. Part II: effectiveness of surgical treatments-a systematic review. Arch Phys Med Rehabil. 2010;91(7):1005-1024.

48. Martin KJ, Floege J, Ketteler M. Bone and mineral metabolism in chronic kidney disease. In: Comprehensive Clinical Nephrology. 5th ed. Philadelphia: Elsevier Saunders; 2014: Chapter 85, 984-999.

49. Gravallese EM, Baker N, Lester S, Kay J, Owen WF Jr. Musculoskeletal manifestations in beta 2-microglobulin amyloidosis. Case discussion. Arthritis Rheum. 1992;35(5):592-602.

50. Maruyama H, Gejyo F, Arakawa M. Clinical studies of destructive spondyloarthropathy in long-term hemodialysis patients. Nephron. 1992;61(1):37-44.

51. Kiss E, Keusch G, Zanetti M, et al. Dialysis-related amyloidosis revisited. AJR Am J Roentgenol. 2005;185(6):1460-1467.

52. Allard JC, Artze ME, Porter G, Ghandur-Mnaymneh L, de Velasco R, Pérez GO. Fatal destructive cervical spondyloarthropathy in two patients on long-term dialysis. Am J Kidney Dis. 1992;19(1): 81-85.

53. Fitzpatrick DC, Jebson PJ, Madey SM, Steyers CM. Upper extremity musculoskeletal manifestations of dialysis-associated amyloidosis. Iowa Orthop J. 1996;16:135-138.

54. Campistol JM, Solé M, Muñoz-Gómez J, Riba J, Ramón R, Revert L. Pathological fractures in patients who have amyloidosis associated with dialysis. A report of five cases. J Bone Joint Surg Am. 1990;72(4):568-574.

55. Yamazaki T, Kawahara N, Arai K, et al. Utility of ultrasonography of the median nerve with a high-frequency probe for the diagnosis of dialysis-related carpal tunnel syndrome. Ther Apher Dial. Epub 2016 Mar 17.

56. Hoshino J, Yamagata K, Nishi S, Nakai S, Masakane I, Iseki K, Tsubakihara Y. Significance of the decreased risk of dialysis-related amyloidosis now proven by results from Japanese nationwide surveys in 1998 and 2010. Nephrol Dial Transplant. 2016;31(4):595-602.

57. Campistol JM. Dialysis-related amyloidosis after renal transplantation. Semin Dial. 2001;14(2):99-102.

58. Mourad G, Argiles A. Renal transplantation relieves the symptoms but does not reverse beta 2-microglobulin-amyloidosis. J Am Soc Nephrol. 1996;7(5):798-804.
59. Tan SY, Baillod R, Brown E, et al Clinical, radiological and serum amyloid $\mathrm{P}$ component scintigraphic feature of beta2-microglobulin amyloidosis associated with continuous ambulatory peritoneal dialysis. Nephrol Dial Transplant. 1999;14(6):1467.

60. OPTN/SRTR Annual Data Report 2014. Am J Transplant. 2016;16(2): $11-46$.

61. Floege J, Koch KM. Beta 2-microglobulin associated amyloidosis and therapy with high flux hemodialysis membranes. Clin Nephrol. 1994;42 (Suppl 1):S52-S56.

62. Canaud B, Bowry SK. Emerging clinical evidence on online hemodiafiltration: does volume of ultrafiltration matter? Blood Purif. 2013;35(1-3):55-62.

63. Furuya R, Kumagai H, Takahashi M. Ultrapure dialysate reduces plasma levels of beta2-microglobulin and pentosidine in hemodialysis patients. Blood Purif. 2005;23(4):311-316.

64. Koda Y, Nishi S, Miyazaki S. Switch from conventional to high-flux membrane reduces the risk of carpal tunnel syndrome and mortality of hemodialysis patients. Kidney Int. 1997;52(4):1096-1101.

65. Rabindranath KS, Strippoli GF, Roderick P, Wallace SA, MacLeod AM, Daly C. Comparison of hemodialysis, hemofiltration, and acetatefree biofiltration for ESRD: systematic review. Am J Kidney Dis. 2005;45(3):437-447.

66. Raj DS, Ouwendyk M, Francoeur R, Pierratos A. beta(2)-microglobulin kinetics in nocturnal haemodialysis. Nephrol Dial Transplant. 2000;15(1):58-64.

67. Benz RL, Siegfried JW, Teehan BP. Carpal tunnel syndrome in dialysis patients: comparison between continuous ambulatory peritoneal dialysis and hemodialysis populations. Am J Kidney Dis. 1988;11(6):473-476.

68. Fry AC, Singh DK, Chandna SM, Farrington K. Relative importance of residual renal function and convection in determining beta-2microglobulin levels in high-flux haemodialysis and on-line haemodiafiltration. Blood Purif. 2007;25(3):295-302.

69. Gejyo F, Homma N, Hasegawa S, Arakawa M. A new therapeutic approach to dialysis amyloidosis: intensive removal of beta 2-microglobulin with adsorbent column. Artif Organs. 1993;17(4):240-243.

70. Homma N, Gejyo F, Hasegawa S, Teramura T, Ei I, Maruyama H, Arakawa M. Effects of a new adsorbent column for removing beta-2-microglobulin from circulating blood of dialysis patients. Contrib Nephrol. 1995;112:164-171.

71. Abe T, Uchita K, Orita H, et al. Effect of beta(2)-microglobulin adsorption column on dialysis-related amyloidosis. Kidney Int. 2003;64(4): $1522-1528$.

72. Otsubo S, Kimata N, Okutsu I, et al. Characteristics of dialysis-related amyloidosis in patients on haemodialysis therapy for more than 30 years. Nephrol Dial Transplant. 2009;24(5):1593-1598.

73. Takenaka R, Fukatsu A, Matsuo S, Ishikawa K, Toriyama T, Kawahara H. Surgical treatment of hemodialysis-related shoulder arthropathy. Clin Nephrol. 1992;38(4):224-230.

74. Stoppini M, Bellotti V. Systemic Amyloidosis: Lessons from ß2-Microglobulin. J Biol Chem. 2015;290(16):9951-9958.

\section{Publish your work in this journal}

The International Journal of Nephrology and Renovascular Disease is an international, peer-reviewed open access journal focusing on the pathophysiology of the kidney and vascular supply. Epidemiology, screening, diagnosis, and treatment interventions are covered as well as basic science, biochemical and immunological studies. The manuscript management system is completely online and includes a very quick and fair peer-review system, which is all easy to use. Visit http://www. dovepress.com/testimonials.php to read real quotes from published authors. 